\title{
Effect of a continuous measure of adherence with infliximab maintenance treatment on inpatient outcomes in Crohn's disease
}

This article was published in the following Dove Press journal:

Patient Preference and Adherence

2 June 2012

Number of times this article has been viewed

\section{Chureen T Carter' \\ Heidi CWaters' \\ Daniel B Smith ${ }^{2}$}

'Health Economics and Outcomes Research, Janssen Scientific Affairs, LLC, Horsham, PA, USA; ${ }^{2}$ Statistics, IMS Health, Watertown, MA, USA

Correspondence: Chureen T Carter Health Economics and Outcomes Research, Janssen Scientific Affairs, LLC, 850 Ridgeview Drive, Horsham, PA 19044, USA

Tel +I 3023764387 ;

+I 8886265696 ext 9543

Fax +| 3023761689

Email ccartel0@its.jnj.com
Background: To assess the impact of a continuous measure of adherence with infliximab maintenance treatment in Crohn's disease (CD) during the first year of treatment on CD-related health care utilization, CD-related hospitalizations, inpatient costs, and length of hospital stay.

Patients and methods: A retrospective claims analysis using the IMS LifeLink Health Plan Claims Database (September 1, 2004, to June 30, 2009) was conducted. Continuous enrollment for 12 months before and 12 months after the index date was required. Patients were required to have at least two claims with an International Classification of Diseases, 9th Revision, Clinical Modification diagnosis code for $\mathrm{CD}$ (555.xx) pre-index and be aged $\geq 18$ years at index. Patients with three infusions during the first 56 days post-index and at least one infusion following day 56 post-index were considered to have maintenance therapy. Adherence and nonadherence were defined as a medication possession ratio of $\geq 80 \%$ and $<80 \%$, respectively.

Results: Four hundred forty-eight patients were included in the analysis (mean age, 42.6 years; $56 \%$ female; mean \pm standard deviation [SD] and median number of infliximab infusions, $7.35 \pm 1.60$ and 8 ). The number of patients who met the definition of adherence was 344 (77\%). CD-related health care utilization was not significantly impacted by adherence except for ancillary services and radiology. Fewer adherent patients were hospitalized compared with nonadherent patients $(9 \%$ versus $16 \% ; P=0.03$ ). Adherent patients had fewer mean $\pm \mathrm{SD}$ and median days in the hospital (5.5 \pm 3.4 and 5 days) compared with nonadherent patients $(13.1 \pm 14.2$ and 8 days; $P=0.01)$. Mean $\pm \mathrm{SD}$ and median hospital costs were significantly greater for nonadherent patients $(\$ 40,822 \pm \$ 49,238$ and $\$ 28,864)$ compared with adherent patients $(\$ 13,704 \pm \$ 10,816$ and $\$ 9938 ; P=0.002)$.

Conclusion: Adherence with maintenance infliximab over 12 months was associated with lower rates of CD-related hospitalizations and inpatient costs and a shorter length of hospital stay.

Keywords: costs, Crohn's disease, hospitalization, infliximab, length of stay, medication adherence

\section{Introduction}

Crohn's disease (CD) is an idiopathic and chronic inflammatory bowel disease that affects approximately $144-198$ per 100,000 people in North America. ${ }^{1}$ It is characterized by episodes of acute symptomatic inflammation of the gut (exacerbations) alternating with periods of reduced disease activity (remission). CD significantly impacts patients' health-related quality of life, having deleterious effects on their physical, social, and emotional well-being. ${ }^{2-5}$ Because there is no known cure for the disease, patients with CD - especially younger patients with early-onset disease - may expect years of medical care, hospitalization, and surgery. ${ }^{3,4}$ Total CD-related treatment costs in the United States (US) using 2003-2004 estimates were \$3.6 billion. ${ }^{6}$ 
Hospitalization and outpatient costs for this time period were $31.4 \%$ and $33.3 \%$ of total CD-related costs, respectively. ${ }^{6}$ Using more recent 2006 estimates, the total economic burden (direct medical and indirect costs) of CD in the US was \$10.9-\$15.5 billion. $^{7}$

A variety of therapeutic agents, including 5-aminosalicylates, systemic corticosteroids, immunomodulators (eg, 6-mercaptopurine, azathioprine, and methotrexate), antibiotics, and biologic agents, have been used in the treatment of $\mathrm{CD}$ in an attempt to induce and maintain clinical remission. ${ }^{5}$ The advent of biologic agents in $\mathrm{CD}$ treatment has dramatically affected treatment expectations in these patients.

Infliximab is a chimeric immunoglobulin G1 monoclonal antibody biologic against tumor necrosis factor- $\alpha$ (TNF- $\alpha$ ). TNF- $\alpha$ has been implicated in stimulating an inappropriate inflammatory gastrointestinal tract response, resulting in diarrhea, fever, abdominal pain, and weight loss associated with CD. ${ }^{8}$ Infliximab has proven to be efficacious in inducing and maintaining clinical remission and mucosal healing in adult and pediatric (aged $\geq 6$ years) patients with moderateto-severe $\mathrm{CD}$ and adult patients with fistulizing CD. ${ }^{9-12}$

One of the goals of CD treatment is to maintain remission in order to prevent exacerbations that require costly hospitalizations and surgeries. ${ }^{13}$ Infliximab has been shown to reduce hospitalizations, surgeries, and procedures, especially when the drug is prescribed as a scheduled maintenance versus periodic treatment regimen. ${ }^{14-19}$

Adherence to a treatment regimen in a chronic condition such as CD is critical for improving patient outcomes over the long term; however, few studies have evaluated the effect of a continuous measure of adherence with biologic agents on health care services utilization, outcomes, and costs in inflammatory bowel disease. The objective of the current study was to assess the observed impact of adherence with infliximab maintenance treatment in CD during the first year of treatment on CD-related health care utilization, hospitalizations, inpatient costs, and length of hospital stay.

\section{Patients and methods}

\section{Data source}

A retrospective, observational cohort was obtained for this analysis using medical and pharmacy claims data from the IMS LifeLink Health Plan Claims Database dated from September 1, 2004, to June 30, 2009. The IMS LifeLink Database comprises fully adjudicated medical and pharmaceutical claims for over 60 million patients from over 90 health plans across the US. ${ }^{20}$ The database content includes hospital admission and discharge dates, dates of service, procedure codes, patient demographics (eg, age, sex), length of hospital stay, medical services and drug costs, and drug information (eg, drug name, dose, strength, days' supply and quantity dispensed, date of service).

\section{Sample selection}

Patients were included in this study if all of the following inclusion criteria were met: the patient had at least one medical claim for infliximab (the date of service on the first claim defined the index date); the patient had at least two diagnoses of CD as defined by the International Classification of Diseases, 9th Revision, Clinical Modification (ICD-9-CM) code of 555.xx during the 12-month pre-index period; there was no evidence of infliximab use during the 6-month preindex period; the patient was aged $\geq 18$ years at the index date; and the patient was continuously enrolled in the health plan for at least 12 months before and 12 months after the index date.

Patients were excluded from the study if any of the following occurred: the patient was not continuously enrolled in the health plan for at least 12 months before and 12 months after the index date; the patient had at least one medical claim with an ICD-9-CM code for psoriasis (696.1), rheumatoid arthritis (714.xx), psoriatic arthritis (696.0), or ankylosing spondylitis (720.xx) during the pre-index period; or the patient had pharmacy National Drug Code claims for infliximab. Patients with a pharmacy National Drug Code claim for infliximab were excluded to focus results on the population of patients receiving all infliximab infusions from health care professionals submitting medical claims. Continuity in the type of claim used for infliximab billing purposes (ie, medical versus pharmacy) ensured that any observed gaps in therapy were not due to administrative errors consequential to changes in the type of claim used. Additionally, the date of service on an infliximab medical claim is representative of the date of actual infusion, whereas the date of service on an infliximab pharmacy claim is representative of when the drug claim was adjudicated by a pharmacy. The index date was defined as the first claim for infliximab received between September 1, 2005, and June 30, 2008.

\section{Definitions and measures}

The continuous measure of adherence was defined as a medication possession ratio (MPR) for patients receiving infliximab maintenance treatment. Patients were considered to have received infliximab maintenance treatment if they 
received three infusions during the first 56 days post-index and one or more infusions following day 56 during the 12-month post-index period. The MPR was calculated as the total days' supply of infliximab administered during the 12-month post-index period divided by 360 .

CD-related utilization of health care services, hospitalization rate, length of hospital stay (days), and inpatient costs were compared between maintenance infliximab-treated patients with adherence (MPR $\geq 80 \%$ ) and patients without adherence (MPR $<80 \%$ ). ${ }^{21,22}$ A claim was considered CDrelated if an ICD-9-CM diagnosis code of CD was present in any position on the claim. A hospitalization was considered CD-related if an ICD-9-CM diagnosis of CD was present in any position on the discharge record. In the IMS LifeLink Database, temporal positioning of the ICD-9-CM diagnosis on the discharge record (eg, first, second, third) is not relevant for determination of reason for hospitalization. Presence of a diagnosis code in any position on the discharge record is indicative of a disease-related hospitalization.

\section{Statistical analyses}

Baseline characteristics between the adherent cohort and nonadherent cohort were compared. Chi-square and $t$-test/ nonparametric Wilcoxon tests were used to test the statistical significance of nominal and continuous variables, respectively. Health care resource utilization and costs were analyzed and compared descriptively between the two adherence cohorts. Statistical significance was defined by a $P$ value $\leq 0.05$.

\section{Results}

The final sample consisted of 448 patients who met the inclusion criteria (Table 1), 344 (77\%) of whom had an MPR $\geq 80 \%$ and were included in the adherence cohort, while the remaining 104 (23\%) patients did not meet adherence (ie, MPR < 80\%). The baseline characteristics were similar between the adherent and nonadherent cohorts (Table 2). The mean \pm standard deviation (SD) age of the total population $(n=448)$ was $42.6 \pm 14.8$ years, and the majority $(56 \%)$ of patients were female. The mean \pm SD and median number of infliximab infusions during the 12-month post-index period in the total population was $7.35 \pm 1.60$ and 8 , respectively.

\section{Pre-infliximab CD-related utilization}

When looking at the 12 months prior to the first infliximab infusion, use of pharmacy (immunomodulators, 5-aminosalicylates, corticosteroids, other biologics, and other pharmacy services) and outpatient services was similar between the adherent and nonadherent cohorts, except for emergency room visits and ancillary/other outpatient services (Table 3). A statistically significant difference in the percentage of patients with at least one emergency room visit claim was observed between the adherent and nonadherent cohorts $(12 \%$ versus $21 \% ; P=0.02)$ for the 12 months pre-index. The median number of claims for ancillary/other outpatient services among patients with at least one claim was significantly higher in the adherent cohort than in the nonadherent cohort (4 versus $3, P=0.02$ ) prior to infliximab exposure. No significant differences were found in the proportion of patients with a hospitalization, length of hospital stay, or inpatient costs (Table 3).

\section{Post-infliximab CD-related utilization}

Utilization of CD-related health care services during the 12 months post-index is presented in Table 4. The mean \pm SD

Table I Attrition of infliximab study population, by reason

\begin{tabular}{|c|c|c|c|c|}
\hline & \multicolumn{2}{|c|}{ Patients excluded } & \multicolumn{2}{|c|}{ Patients remaining } \\
\hline & $\mathbf{n}$ & $\%$ & $\mathbf{n}$ & $\%$ \\
\hline Total number of patients before any attrition & & & 18,500 & 100.0 \\
\hline Less than 18 years of age & 609 & 3.3 & $|7,89|$ & 96.7 \\
\hline Not enrolled for 360 days pre-index & 7631 & 41.2 & 10,260 & 55.5 \\
\hline Not enrolled for 360 days post-index & 2115 & $\mathrm{II} .4$ & 8145 & 44.0 \\
\hline No evidence ( $\geq 2$ claim days) of pre-index CD & 5971 & 32.3 & 2174 & 11.8 \\
\hline Has claim for an exclusionary comorbidity in 360 days pre-index & 208 & I.I & 1966 & 10.6 \\
\hline Has infliximab claim in 180 days pre-index & 782 & 4.2 & 1184 & 6.4 \\
\hline Has colectomy within 84 days post-index & 27 & 0.1 & 1157 & 6.3 \\
\hline Has infliximab NDC claim post-index & 66 & 0.4 & 1091 & 5.9 \\
\hline Has non-index biologic post-index & 78 & 0.4 & 1013 & 5.5 \\
\hline Data quality issue & 16 & 0.1 & 997 & 5.4 \\
\hline Does not have three induction infusions & 513 & 2.8 & 484 & 2.6 \\
\hline Does not have maintenance infusions & 36 & 0.2 & 448 & 2.4 \\
\hline Patients available for analysis & & & 448 & 2.4 \\
\hline
\end{tabular}

Abbreviations: CD, Crohn's disease; NDC, National Drug Code. 
Table 2 Demographic characteristics by cohort

\begin{tabular}{|c|c|c|c|c|}
\hline Characteristic & $\begin{array}{l}\text { Total, } \\
n=448\end{array}$ & $\begin{array}{l}\text { Adherent cohort } \\
\text { (MPR } \geq 80 \%) \\
n=344\end{array}$ & $\begin{array}{l}\text { Nonadherent cohort } \\
\text { (MPR }<80 \%) \\
n=104\end{array}$ & $P$ value \\
\hline \multicolumn{5}{|l|}{ Age, years } \\
\hline Mean (SD) & $42.6(14.8)$ & $42.4(14.9)$ & $43.3(14.2)$ & \\
\hline Median & 43 & 42 & 45 & 0.48 \\
\hline \multicolumn{5}{|l|}{ Sex, n (\%) } \\
\hline Female & $25 \mid(56)$ & $199(58)$ & $52(50)$ & \\
\hline Male & $197(44)$ & $145(42)$ & $52(50)$ & 0.16 \\
\hline Payer type, n (\%) & & & & $N / A$ \\
\hline Commercial plan & $424(95)$ & $325(94)$ & $99(95)$ & \\
\hline Medicaid & $2(<I)$ & $\mathrm{I}(<\mathrm{I})$ & $I(I)$ & \\
\hline Medicare risk & $10(2)$ & $10(3)$ & $0(0)$ & \\
\hline Self-insured & $12(3)$ & $8(2)$ & $4(4)$ & \\
\hline Region, n (\%) & & & & 0.33 \\
\hline Northeast & $69(15)$ & $48(14)$ & $21(20)$ & \\
\hline Midwest & $187(42)$ & $149(43)$ & $38(37)$ & \\
\hline South & $132(29)$ & $103(30)$ & $29(28)$ & \\
\hline West & $60(13)$ & $44(13)$ & $16(15)$ & \\
\hline First infliximab infusion place of service, $n(\%)$ & & & & $\mathrm{N} / \mathrm{A}$ \\
\hline Outpatient office & $295(66)$ & $234(68)$ & $61(59)$ & \\
\hline Outpatient hospital & $60(13)$ & $45(13)$ & $15(14)$ & \\
\hline Inpatient hospital & $48(11)$ & $34(10)$ & $14(13)$ & \\
\hline Unknown & $30(7)$ & $22(6)$ & $8(8)$ & \\
\hline All other POS codes & $15(3)$ & $9(3)$ & $6(6)$ & \\
\hline
\end{tabular}

Abbreviations: MPR, medication possession ratio; N/A, not applicable; POS, place of service; SD, standard deviation.

number of infliximab pharmacy claims was significantly greater in patients with adherence than those without $(8.1 \pm 0.9$ versus $5.0 \pm 1.0 ; P<0.001)$. There were no statistically significant differences in utilization of specific CD-related pharmacy services (ie, immunomodulators, 5-aminosalicylates, corticosteroids, and other pharmacy services) during the post-index period. The median number of ancillary and other outpatient services claims among patients with at least one claim was significantly greater in the adherent cohort compared with the nonadherent cohort (22 versus 18; $P<0.001$ ); however, adherent patients with at least one radiology claim had fewer median radiology claims compared with nonadherent patients ( 2 versus $3 ; P=0.004$ ).

Post-index CD-related hospitalizations, length of hospital stay, and inpatient costs are reported in Table 5. A lower proportion of patients in the adherent cohort was hospitalized than in the nonadherent cohort ( $9 \%$ versus $16 \%, P=0.03$ ). Among all patients, the mean \pm SD number of hospitalizations was lower in those with adherence than in those without $(0.10 \pm 0.36$ versus $0.21 \pm 0.52)$, as were inpatient costs ( $\$ 1235 \pm 5067$ versus $\$ 6673 \pm 24,631)$.

Among the subset of patients with at least one hospitalization, patients demonstrating adherence to infliximab had significantly shorter median length of hospital stay compared with those without adherence ( 5 versus 8 days; $P=0.01$ ).
Patients with adherence also trended toward fewer mean \pm SD hospitalizations than patients without adherence, although the difference was not statistically significant $(1.2 \pm 0.5$ versus $1.3 \pm 0.5$ ). Mean $\pm \mathrm{SD}$ inpatient costs, however, were significantly lower for the adherent cohort than for the nonadherent cohort $(\$ 13,704 \pm 10,816$ versus $\$ 40,822 \pm 49,238 ; P=0.002)$. Median costs are presented in Figure 1.

\section{Discussion}

Nonadherence with treatment regimens in chronic diseases is a ubiquitous problem. Nonadherence with oral therapies in gastrointestinal disease and its subsequent impact on medical costs is well documented. ${ }^{23-35}$ Reported nonadherence rates for oral medications in inflammatory bowel disease range between $7 \%$ and $72 \%$, with most studies reporting nonadherence rates between $30 \%$ and $45 \%{ }^{28} \mathrm{Few}$ studies, however, have evaluated the impact of adherence on biologic therapies in inflammatory bowel disease, and even fewer studies have focused on the impact of adherence with maintenance therapy specifically in patients with $\mathrm{CD}$. To our knowledge, as of the date of this publication, this is the first study to evaluate the impact of a continuous measure of adherence with infliximab maintenance therapy, as measured by MPRs over 12 months, in CD treatment. 
Table 3 Pre-index utilization of CD-related health care services

\begin{tabular}{|c|c|c|c|}
\hline Services & $\begin{array}{l}\text { Adherent cohort } \\
\text { (MPR } \geq 80 \%) \\
n=344\end{array}$ & $\begin{array}{l}\text { Nonadherent } \\
\text { cohort } \\
\text { (MPR }<80 \%) \\
n=104\end{array}$ & $P$ value \\
\hline \multicolumn{4}{|l|}{ Pharmacy services } \\
\hline \multicolumn{4}{|l|}{ Immunomodulators } \\
\hline Patients with at least one claim, $\mathrm{n}(\%)$ & $179(52)$ & $53(5 \mathrm{I})$ & 0.85 \\
\hline \multicolumn{4}{|l|}{ Claims } \\
\hline Mean (SD) & $4.87(3.6 I)$ & $4.32(3.46)$ & \\
\hline Median & 4 & 3 & 0.32 \\
\hline \multicolumn{4}{|l|}{ 5-aminosalicylates } \\
\hline Patients with at least one claim, $\mathrm{n}(\%)$ & $184(53)$ & $50(48)$ & 0.33 \\
\hline \multicolumn{4}{|l|}{ Claims } \\
\hline Mean (SD) & $5.22(3.6 \mathrm{I})$ & $4.82(3.06)$ & \\
\hline Median & 4 & 4 & 0.70 \\
\hline \multicolumn{4}{|l|}{ Corticosteroids } \\
\hline Patients with at least one claim, $\mathrm{n}(\%)$ & $214(62)$ & $57(55)$ & 0.18 \\
\hline \multicolumn{4}{|l|}{ Claims } \\
\hline Mean (SD) & $3.63(2.73)$ & $3.77(2.52)$ & \\
\hline Median & 3 & 4 & 0.54 \\
\hline \multicolumn{4}{|l|}{ Other pharmacy services } \\
\hline Patients with at least one claim, $\mathrm{n}(\%)$ & $68(20)$ & $13(13)$ & 0.09 \\
\hline \multicolumn{4}{|l|}{ Claims } \\
\hline Mean (SD) & $2.76(3.22)$ & $3.31(2.75)$ & \\
\hline Median & 2 & 3 & 0.20 \\
\hline \multicolumn{4}{|l|}{ Outpatient services } \\
\hline \multicolumn{4}{|l|}{ Emergency room visits } \\
\hline Patients with at least one claim, n (\%) & $4 I(12)$ & $22(2 I)$ & 0.02 \\
\hline \multicolumn{4}{|l|}{ Claims } \\
\hline Mean (SD) & $1.44(0.95)$ & $\mathrm{I} .4 \mathrm{I}(0.67)$ & \\
\hline Median & 1 & I & 0.63 \\
\hline \multicolumn{4}{|l|}{ Laboratory and pathology } \\
\hline Patients with at least one claim, n (\%) & $287(83)$ & $93(89)$ & 0.14 \\
\hline \multicolumn{4}{|l|}{ Claims } \\
\hline Mean (SD) & $12.22(13.65)$ & $11.90(10.60)$ & \\
\hline Median & 9 & 10 & 0.67 \\
\hline \multicolumn{4}{|l|}{ Radiology } \\
\hline Patients with at least one claim, $\mathrm{n}(\%)$ & $173(50)$ & $53(5 \mathrm{I})$ & 0.91 \\
\hline \multicolumn{4}{|l|}{ Claims } \\
\hline Mean (SD) & $2.64(1.94)$ & $2.30(1.56)$ & \\
\hline Median & 2 & 2 & 0.36 \\
\hline \multicolumn{4}{|l|}{ Physician office visits } \\
\hline Patients with at least one claim, $\mathrm{n}(\%)$ & $309(90)$ & $92(88)$ & 0.69 \\
\hline \multicolumn{4}{|l|}{ Claims } \\
\hline Mean (SD) & $4.75(3.45)$ & $5.57(4.38)$ & \\
\hline Median & 4 & 5 & 0.07 \\
\hline \multicolumn{4}{|l|}{ Surgical services } \\
\hline Patients with at least one claim, $\mathrm{n}(\%)$ & $158(46)$ & $48(46)$ & 0.97 \\
\hline \multicolumn{4}{|l|}{ Claims } \\
\hline Mean (SD) & I.5I (0.94) & $1.33(0.91)$ & \\
\hline Median & 1 & I & 0.06 \\
\hline Ancillary/all other outpatient services & & & \\
\hline Patients with at least one claim, $\mathrm{n}(\%)$ & $263(76)$ & $77(74)$ & 0.61 \\
\hline Claims & & & \\
\hline Mean (SD) & $6.33(6.88)$ & $5.22(7.63)$ & \\
\hline Median & 4 & 3 & 0.02 \\
\hline Inpatient services & & & \\
\hline Patients with at least one hospitalization, $\mathrm{n}(\%)$ & $74(22)$ & $21(20)$ & 0.77 \\
\hline
\end{tabular}


Table 3 (Continued)

\begin{tabular}{|c|c|c|c|}
\hline Services & $\begin{array}{l}\text { Adherent cohort } \\
\text { (MPR } \geq 80 \%) \\
n=344\end{array}$ & $\begin{array}{l}\text { Nonadherent } \\
\text { cohort } \\
\text { (MPR }<80 \% \text { ), } \\
n=104\end{array}$ & $P$ value \\
\hline \multicolumn{4}{|c|}{ Number of hospitalizations } \\
\hline Mean (SD) & $1.22(0.50)$ & I.I 4 (0.48) & \\
\hline Median & 1 & I & $0.4 I$ \\
\hline \multicolumn{4}{|c|}{ Number of hospital days } \\
\hline Mean (SD) & $7.80(7.26)$ & $6.38(4.04)$ & \\
\hline Median & 6 & 5 & 0.48 \\
\hline \multicolumn{4}{|c|}{ Hospitalization costs, $\$$} \\
\hline Mean (SD) & $16,966(18,286)$ & $12,046(86 \mid 7)$ & \\
\hline Median & 10,178 & 8462 & 0.32 \\
\hline
\end{tabular}

Abbreviations: $C D$, Crohn's disease; MPR, medication possession ratio; SD, standard deviation.

In the current study, $23 \%$ of patients with CD met the criteria for nonadherence with infliximab maintenance therapy at 12 months. Kane et a ${ }^{29}$ reported a higher nonadherence rate of $34 \%$ with maintenance infliximab treatment over 12 months in a retrospective study of patients with CD from the Integrated Health Care Information Service claims database. That study, however, did not evaluate adherence using MPR; adherence was measured by the number of infusions administered over one year. The adherence rate of $77 \%$ in the current study is more consistent with the adherence rate of $70 \%-80 \%$ with TNF- $\alpha$ inhibitors in patients with rheumatoid arthritis over 12 months, as reported by Tang et al..$^{30}$

Medication adherence, as defined by the International Society for Pharmacoeconomics and Outcomes Research, is the "extent to which a patient acts in accordance with the prescribed interval and dose of a dosing regimen. ${ }^{36}$ As per the methodological standards of the International Society for Pharmacoeconomics and Outcomes Research, medication adherence may be estimated by an MPR calculation; however, unlike oral or patient self-administered medications, intravenous medications administered by health care professionals (versus patients) may have a greater degree of physician input and control on the prescribed interval and dose. This poses a challenge to patient adherence research for a treatment like infliximab yet offers a view on overall adherence compared with prescribing recommendations; this adherence estimate is the result of treatment-related shared decision-making between the patient and health care professional.

The most notable finding in this study is the economic impact of adherence with maintenance infliximab on hospitalizations and inpatient costs. A significantly lower proportion of adherent patients were hospitalized compared with nonadherent patients. In addition, adherent patients who were hospitalized had a significantly shorter length of hospital stay and significantly lower hospital costs. Another retrospective study used a medical claims database to evaluate the impact of adherence with oral aminosalicylate medications in nonspecified gastrointestinal disease. Shaya et a ${ }^{25}$ demonstrated that nonadherent patients incurred higher costs for hospital admission, outpatient visits, and office visits. Nonadherent patients incurred an additional annual cost of $\$ 1875$ in total health care expenditures; however, medication adherence was not measured in that study using the MPR method as used in the current study, and the database used in that study was limited to enrollees of a private insurance plan in Maryland.

In the Kane et $\mathrm{al}^{29}$ study that evaluated the impact of adherence on health care utilization and costs (as measured by the number of infusions over one year), nonadherence was also associated with significantly greater CD-related medical costs $(94 \%)$ and hospitalization costs $(250 \%)$ as well as outpatient costs $(68 \%)$ when compared with adherent patients. Although the Integrated Health Care Information Service claims database used in the Kane study is a large database covering 25 million managed care lives, it is a smaller and less diverse database than the IMS LifeLink Database used in the current study. The IMS LifeLink Database includes over 90 health plans from across the US and contributes data from 60 million covered lives. It is considered a more diverse database in terms of health plans and may therefore be more nationally representative of this patient population.

The maintenance of remission and prevention of exacerbations that lead to costly hospitalizations and surgeries are the main goals in $\mathrm{CD}$ treatment. Hospitalizations for $\mathrm{CD}$ account for approximately half of all direct medical costs $(53 \%-66 \%)$, and approximately half of all hospitalized patients will undergo a surgical procedure. ${ }^{7,31-33}$ The estimated length of 
Table 4 Post-index utilization of CD-related health care services

\begin{tabular}{|c|c|c|c|}
\hline Services & $\begin{array}{l}\text { Adherent cohort } \\
\text { (MPR } \geq 80 \%) \\
n=344\end{array}$ & $\begin{array}{l}\text { Nonadherent cohort } \\
\text { (MPR }<80 \%) \\
n=104\end{array}$ & $P$ value \\
\hline \multicolumn{4}{|l|}{ Pharmacy services } \\
\hline \multicolumn{4}{|l|}{ Infliximab } \\
\hline Patients with at least one claim, $\mathrm{n}(\%)$ & $344(100)$ & $104(100)$ & \\
\hline \multicolumn{4}{|l|}{ Claims } \\
\hline Mean (SD) & $8.06(0.93)$ & $4.99(1.00)$ & \\
\hline Median & 8 & 5 & $<0.001$ \\
\hline \multicolumn{4}{|l|}{ Immunomodulators } \\
\hline Patients with at least one claim, $\mathrm{n}(\%)$ & $158(46)$ & $46(44)$ & 0.76 \\
\hline \multicolumn{4}{|l|}{ Claims } \\
\hline Mean (SD) & $6.87(3.85)$ & $5.80(3.76)$ & \\
\hline Median & 7 & 5 & 0.08 \\
\hline \multicolumn{4}{|l|}{ 5-aminosalicylates } \\
\hline Patients with at least one claim, $\mathrm{n}(\%)$ & $112(33)$ & $33(32)$ & 0.87 \\
\hline \multicolumn{4}{|l|}{ Claims } \\
\hline Mean (SD) & $5.26(3.60)$ & $4.45(2.87)$ & \\
\hline Median & 4 & 4 & 0.35 \\
\hline \multicolumn{4}{|l|}{ Corticosteroids } \\
\hline Patients with at least one claim, $\mathrm{n}(\%)$ & 135 (39) & $45(43)$ & 0.46 \\
\hline \multicolumn{4}{|l|}{ Claims } \\
\hline Mean (SD) & $3.02(2.63)$ & $4.07(3.58)$ & \\
\hline Median & 2 & 2 & 0.12 \\
\hline \multicolumn{4}{|l|}{ Other pharmacy services } \\
\hline Patients with at least one claim, $\mathrm{n}(\%)$ & $254(74)$ & $79(76)$ & 0.66 \\
\hline \multicolumn{4}{|l|}{ Claims } \\
\hline Mean (SD) & $9.08(6.09)$ & $8.25(6.60)$ & \\
\hline Median & 8 & 6 & 0.10 \\
\hline \multicolumn{4}{|l|}{ Outpatient services } \\
\hline \multicolumn{4}{|l|}{ Emergency room visits } \\
\hline Patients with at least one claim, $\mathrm{n}(\%)$ & $42(12)$ & $19(18)$ & 0.11 \\
\hline \multicolumn{4}{|l|}{ Claims } \\
\hline Mean (SD) & $1.52(0.83)$ & $1.26(0.56)$ & \\
\hline Median & 1 & 1 & 0.24 \\
\hline \multicolumn{4}{|l|}{ Laboratory and pathology } \\
\hline Patients with at least one claim, $\mathrm{n}(\%)$ & $277(8 \mathrm{I})$ & $87(84)$ & 0.47 \\
\hline \multicolumn{4}{|l|}{ Claims } \\
\hline Mean (SD) & $14.86(18.10)$ & I5.53 (I7.97) & \\
\hline Median & 10 & $\mathrm{II}$ & 0.42 \\
\hline \multicolumn{4}{|l|}{ Radiology } \\
\hline Patients with at least one claim, $\mathrm{n}(\%)$ & $99(29)$ & $35(34)$ & 0.34 \\
\hline \multicolumn{4}{|l|}{ Claims } \\
\hline Mean (SD) & $2.21(1.66)$ & $3.5 I(2.64)$ & \\
\hline Median & 2 & 3 & 0.004 \\
\hline \multicolumn{4}{|l|}{ Physician office visits } \\
\hline Patients with at least one claim, $\mathrm{n}(\%)$ & $314(9 \mid)$ & $98(94)$ & 0.33 \\
\hline \multicolumn{4}{|l|}{ Claims } \\
\hline Mean (SD) & $6.49(4.77)$ & $6.40(5.87)$ & \\
\hline Median & 6 & 5 & 0.69 \\
\hline Surgical services & & & \\
\hline Patients with at least one claim, $\mathrm{n}(\%)$ & $96(28)$ & $37(36)$ & 0.13 \\
\hline Claims & & & \\
\hline Mean (SD) & $2.05(2.02)$ & $2.03(1.46)$ & \\
\hline Median & 1 & 1 & 0.38 \\
\hline Ancillary/all other outpatient services & & & \\
\hline Patients with at least one claim, $\mathrm{n}(\%)$ & $336(98)$ & $102(98)$ & 0.81 \\
\hline
\end{tabular}


Table 4 (Continued)

\begin{tabular}{lll}
\hline Services & $\begin{array}{l}\text { Adherent cohort } \\
\text { (MPR } \geq \mathbf{8 0 \% )}, \\
\mathbf{n}=\mathbf{3 4 4}\end{array}$ & $\begin{array}{l}\text { Nonadherent cohort } \\
\text { (MPR }<\mathbf{8 0 \% ) , ~} \\
\mathbf{n}=1 \mathbf{0 4}\end{array}$ \\
\hline Claims & & $\mathbf{P}$ value \\
Mean (SD) & $25.38(14.30)$ & $19.98(13.91)$ \\
Median & 22 & 18 \\
\hline
\end{tabular}

Abbreviations: CD, Crohn's disease; MPR, medication possession ratio; SD, standard deviation.

hospital stay in the US is 8.0 days for nonsurgical treatment and 9.6 days for surgical treatment. ${ }^{33}$ The average cost per hospitalization was $\$ 37,459$ in the US (2006 adjusted dollars) and is rising. ${ }^{7}$ The cost of hospitalizing patients with $\mathrm{CD}$ in the US increased from $\$ 762$ million to $\$ 1330$ million dollars (inflation-adjusted) between 1998 and 2004. ${ }^{34}$ Most importantly, the cost of illness in patients with inflammatory bowel disease who require hospitalization can be 20 times higher than that of ambulatory patients who remain in remission. ${ }^{35}$ Therefore, the economic burden that results from not maintaining remission in patients with CD is substantial. Therapy that can limit the need for hospitalization and/or surgery may reduce the overall costs of care and improve health-related quality of life in patients with CD.

Several clinical trials and retrospective studies have shown that scheduled maintenance treatment with infliximab resulted in a significant reduction in the number and duration of CD-related hospitalizations, fewer surgeries and procedures, fewer developed antibodies, and higher rates of mucosal healing compared with episodic treatment using infliximab. ${ }^{14-19}$ A recent retrospective 3-year study of 104 patients with CD demonstrated that patients who continued an uninterrupted maintenance dosing regimen of infliximab had fewer incidences of hospitalization, surgery, and disability than patients who had an irregular or interrupted regimen of infliximab prior to initiating a scheduled maintenance regimen. ${ }^{37}$ The data from this study expand the findings from previous infliximab studies by demonstrating the importance of maintaining adherence with infliximab in reducing the costs associated with $\mathrm{CD}$-related hospitalizations and inpatient costs in a larger sample.

Only a few CD-related health care services in this study were impacted over 12 months by nonadherence with infliximab. Significant differences in radiology and ancillary outpatient services were noted between adherent and nonadherent patients. Given that ancillary services included billing for intravenous administration of infliximab, it is not surprising that the adherent group with the greater number of infusions would also require more ancillary services. These data also suggest that nonadherence to infliximab impacts utilization of outpatient services to a lesser extent than inpatient costs. Although the administrative and pharmacy costs of any biologic agent may be higher than oral medication costs, these data suggest that adherence to maintenance

Table 5 Post-index CD-related hospitalizations, lengths of hospital stay, and inpatient costs by cohort

\begin{tabular}{|c|c|c|c|c|}
\hline & $\begin{array}{l}\text { All patients, } \\
n=448\end{array}$ & $\begin{array}{l}\text { Adherent cohort } \\
\text { (MPR } \geq 80 \%), \\
n=344\end{array}$ & $\begin{array}{l}\text { Nonadherent cohort } \\
\text { (MPR }<80 \%) \\
n=104\end{array}$ & $P$ value \\
\hline $\begin{array}{l}\text { Hospitalizations among all patients, } \\
\text { mean (SD) }\end{array}$ & $0.13(0.40)$ & $0.10(0.36)$ & $0.21(0.52)$ & \\
\hline $\begin{array}{l}\text { Hospitalization costs among all patients, } \\
\text { mean (SD) }\end{array}$ & $\$ 2497(\$ 12,837)$ & $\$ 1235(\$ 5067)$ & $\$ 6673(\$ 24,631)$ & \\
\hline $\begin{array}{l}\text { Patients with at least one hospitalization, } \\
\mathrm{n}(\%)\end{array}$ & $48(\mathrm{II})$ & $31(9)$ & $17(16)$ & 0.03 \\
\hline \multicolumn{5}{|l|}{ Number of hospitalizations } \\
\hline Mean (SD) & I.2(0.5) & I.2(0.5) & I.3 (0.5) & \\
\hline Median & I & 1 & 1 & 0.20 \\
\hline \multicolumn{5}{|l|}{ Number of hospital days } \\
\hline Mean (SD) & $8.2(9.5)$ & $5.5(3.4)$ & I3.I (14.2) & \\
\hline Median & 6 & 5 & 8 & 0.01 \\
\hline \multicolumn{5}{|l|}{ Hospitalization costs, $\$$} \\
\hline Mean (SD) & $23,308(32,738)$ & I3,704 (I0,8|6) & $40,822(49,238)$ & \\
\hline Median & 15,796 & 9938 & 28,864 & 0.002 \\
\hline
\end{tabular}

Abbreviations: $C D$, Crohn's disease; MPR, medication possession ratio; SD, standard deviation. 


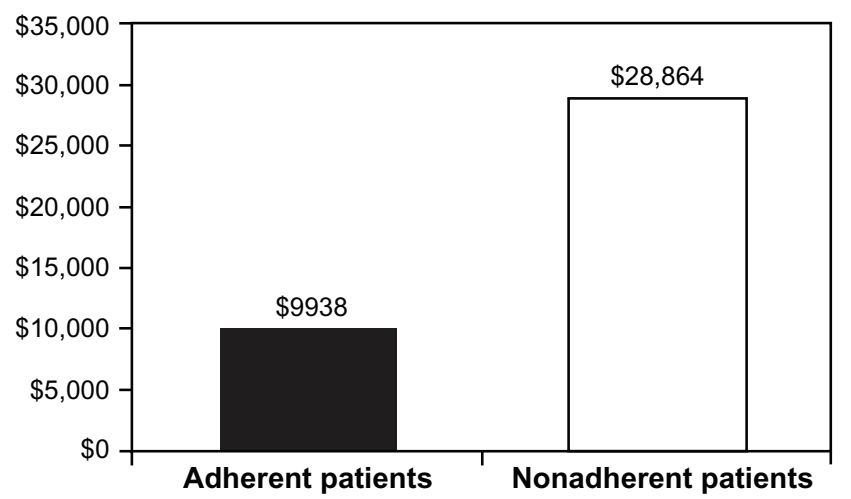

Figure I Median Crohn's disease-related costs of hospitalization among patients with Crohn's disease and with at least one hospitalization.

Note: $P=0.002$, adherent versus nonadherent patients.

infliximab is a value-added treatment for $\mathrm{CD}$. The economic benefits of adherence to infliximab may be realized in terms of reduced hospitalizations, length of hospital stay, and inpatient costs. The cost of infliximab administered in the inpatient setting was included in the overall inpatient cost results. The cost of infliximab administered in the outpatient setting was not included. Future analyses may include an assessment of the impact of infliximab on total CD-related health care resource utilization and costs and not limited only to the inpatient setting.

One of the advantages of using an administrative claims database to report pharmacoeconomic outcomes is the ability to examine primary health care data in a real-life setting rather than in a highly controlled clinical trial setting. Another advantage of the current study design over previous adherence studies is that medians (versus means) are reported. The presence of outliers is an inherent flaw in pharmacoeconomic cost analyses. Reporting medians in this type of study reduces the influence of outliers on the dataset.

The limitations of a claims database are well known and include the same biases that occur in any retrospective observational study, including inability to determine reasons for lack of adherence or discontinuation of drug therapy, lack of socioeconomic information, lack of clinical data from medical charts that might be associated with health care costs, and lack of detailed information on disease activity and duration. No statistical adjustments were performed when comparing health care utilization and costs between the adherent and nonadherent groups because baseline characteristics were mostly similar between cohorts; however, similarities in observable characteristics at baseline may not always exist in every adherent and nonadherent $\mathrm{CD}$ population. It is recommended that statistical adjustments be made in any $\mathrm{CD}$ population where baseline characteristics differ.
Unfortunately, no method or mechanism was used in this administrative claims database analysis to adjust for unobservable characteristics (eg, travel distance to site for infliximab infusion or infliximab supply availability to health care professionals) that may have had a role in determining the level of observed adherence. Information regarding the dose of infliximab given at each infusion was not available, so while the infusion patterns were consistent with prescribing recommendations, the actual dose was unknown. Finally, this database contained information largely from commercial payers in the US; therefore, the results may not be generalizable to patients covered by Medicare or Medicaid or to patients outside the US.

\section{Conclusion}

In this study, adherence with maintenance infliximab over 12 months was associated with a lower rate of CD-related hospitalizations. Furthermore, among those who were hospitalized, adherence had an observed beneficial economic impact, as evidenced by lower CD-related inpatient costs and a shorter length of hospital stay. Additional comparative studies are needed to compare adherence with more frequently versus less frequently administered therapies for the treatment of $\mathrm{CD}$ and their resulting effects on clinical and health economic outcomes.

\section{Disclosure}

Financial support for this work was provided by Janssen Scientific Affairs, LLC. The authors acknowledge Kim Poinsett-Holmes at Poinsett Publications, Inc., for assistance with the preparation and editing of this manuscript, as well as Gianna Paone at Janssen Services, LLC, for editorial and submission support. Kim Poinsett-Holmes was reimbursed by Janssen Scientific Affairs, LLC, for her editorial assistance in this work. CTC is an employee of Janssen Scientific Affairs, LLC, as was HCW at the time of the analysis and manuscript preparation (currently employed at S2 Statistical Solutions, Inc., Cincinnati, OH, USA). These data have been previously presented, in part, at the Academy of Managed Care Pharmacy Meeting, October 13-15, 2010, St Louis, MO, and at the 2010 Advances in Inflammatory Bowel Diseases, Crohn's \& Colitis Foundation's Clinical \& Research Conference, December 9-12, 2010, Hollywood, FL.

\section{References}

1. Loftus EV Jr, Schoenfeld P, Sandborn WJ. The epidemiology and natural history of Crohn's disease in population-based patient cohorts from North America: a systematic review. Aliment Pharmacol Ther. 2002;16(1): 51-60. 
2. Von Wietersheim J, Kessler H. Psychotherapy with chronic inflammatory bowel disease patients: a review. Inflamm Bowel Dis. 2006;12(12): 1175-1184.

3. Akobeng AK. Crohn's disease: current treatment options. Arch Dis Child. 2008;93(9):787-792.

4. Karwowski CA, Keljo D, Szigethy E. Strategies to improve quality of life in adolescents with inflammatory bowel disease. Inflamm Bowel Dis. 2009;15(11):1755-1764.

5. Katz JA. Management of inflammatory bowel disease in adults. J Dig Dis. 2007;8(2):65-71.

6. Kappelman MD, Rifas-Shiman SL, Porter CQ, et al. Direct health care costs of Crohn's disease and ulcerative colitis in US children and adults. Gastroenterology. 2008;135(6):1907-1913.

7. Yu AP, Cabanilla LA, Wu EQ, Mulani PM, Chao J. The costs of Crohn's disease in the United States and other Western countries: a systematic review. Curr Med Res Opin. 2008;24(2):319-328.

8. Abraham C, Cho JH. Inflammatory bowel disease. NEngl J Med. 2009; 361(21):2066-2078.

9. Targan SR, Hanauer SB, van Deventer SJH, et al; the Crohn's Disease cA2 Study Group. A short-term study of chimeric monoclonal antibody cA2 to tumor necrosis factor alpha for Crohn's disease. $N$ Engl J Med. 1997;337(15):1029-1035.

10. Hanauer SB, Feagan BG, Lichtenstein GR, et al; and the ACCENT I Study Group. Maintenance infliximab for Crohn's disease: the ACCENT I randomised trial. Lancet. 2002:359(9317):1541-1549.

11. Sands BE, Anderson FH, Bernstein $\mathrm{CN}$, et al. Infliximab maintenance therapy for fistulizing Crohn's disease. $N$ Engl J Med. 2004;350(9): 876-885.

12. Present DH, Rutgeerts $\mathrm{P}$, Targan $\mathrm{S}$, et al. Infliximab for the treatment of fistulas in patients with Crohn's disease. $N$ Engl J Med. 1999;340(18):1398-1405.

13. Lichtenstein GR, Hanauer SB, Sandborn WJ; and the Practice Parameters Committee of the American College of Gastroenterology. Management of Crohn's disease in adults. Am J Gastroenterol. 2009; 104(2):465-483.

14. Lichtenstein GR, Yan S, Bala M, Blank M, Sands BE. Infliximab maintenance treatment reduces hospitalizations, surgeries, and procedures in fistulizing Crohn's disease. Gastroenterology. 2005; 128(4):862-869

15. Colombel JF, Rutgeerts P, Yan S, et al. Infliximab (Remicade) maintenance treatment results in lower hospitalization rate in Crohn's disease patients. Poster presented at Digestive Disease Week, May 19-22, 2002, San Francisco, CA.

16. Williams JB, Cross RK, Thameen D, et al. Long-term infliximab maintenance infusion regimens and rates of hospitalization, surgery and disability in Crohn's disease patients [Abstract]. Gastroenterology. 2005;128(4 Suppl 2):A-589.

17. Williams JB, Weber LR, Beaulieu DB, et al. Long-term infliximab maintenance infusion regimens and rates of hospitalization, surgery, and disability in Crohn's disease [Abstract]. Gastroenterology. 2006; 130(4 Suppl 2):A-143.

18. Schnitzler F, Fidder H, Ferrante M, et al. Long-term outcome of treatment with infliximab in 614 patients with Crohn's disease: results from a single-centre cohort. Gut. 2009;58(4):492-500.

19. Rutgeerts P, Feagan BG, Lichtenstein GR, et al. Comparison of scheduled and episodic treatment strategies of infliximab in Crohn's disease. Gastroenterology. 2004;126(2):402-413.

Patient Preference and Adherence

\section{Publish your work in this journal}

Patient Preference and Adherence is an international, peer-reviewed, open access journal focusing on the growing importance of patient preference and adherence throughout the therapeutic continuum. Patient satisfaction, acceptability, quality of life, compliance, persistence and their role in developing new therapeutic modalities and compounds to
20. PharMetrics Inc. LifeLink Health Plan Claims Database. Watertown, MA: IMS Health; 2010.

21. DiMatteo MR, Giordani PJ, Lepper HS, Croghan TW. Patient adherence and medical treatment outcomes: a meta-analysis. Med Care. 2002;40(9):794-811.

22. DiMatteo MR. Variations in patients' adherence to medical recommendations: a quantitative review of 50 years of research. Med Care. 2004;42(3):200-209.

23. Bokemeyer B, Teml A, Roggel C, et al. Adherence to thiopurine treatment in out-patients with Crohn's disease. Aliment Pharmacol Ther. 2007;26(2):217-225.

24. Mantzaris GJ, Roussos A, Kalantzis C, Koilakou S, Raptis N, Kalantzis N. How adherent to treatment with azathioprine are patients with Crohn's disease in long-term remission? Inflamm Bowel Dis. 2007;13(4):446-450.

25. Shaya FT, El Khoury AC, Wong W, et al. Persistence with pharmacotherapy for gastrointestinal disease: associated costs of health care. PT. 2006;31(11):657-665

26. Higgins PD, Rubin DT, Kaulback K, Schoenfield PS, Kane SV. Systematic review: impact of non-adherence to 5-aminosalicylic acid products on the frequency and cost of ulcerative colitis flares. Aliment Pharmacol Ther. 2009;29(3):247-257.

27. Kane S, Shaya F. Medication non-adherence is associated with increased medical health care costs. Dig Dis Sci. 2008;53(4):1020-1024.

28. Jackson CA, Clatworthy J, Robinson A, Horne R. Factors associated with non-adherence to oral medication for inflammatory bowel disease: a systematic review. Am J Gastroenterol. 2010;105(3):525-539.

29. Kane SV, Chao J, Mulani PM. Adherence to infliximab maintenance therapy and health care utilization and costs by Crohn's disease patients. Adv Ther. 2009;26(10):936-946.

30. Tang B, Rahman M, Waters HC, Callegari P. Treatment persistence with adalimumab, etanercept, or infliximab in combination with methotrexate and the effects on health care costs in patients with rheumatoid arthritis. Clin Ther. 2008;30(7):1375-1384.

31. Cohen RD, Larson LR, Roth JM, Becker RV, Mummert LL. The cost of hospitalization in Crohn's disease. Am J Gastroenterol. 2000;95(2): 524-530.

32. Blomqvist P, Ekbom A. Inflammatory bowel disease: health care and costs in Sweden in 1994. Scand J Gastroenterol. 1997;32(11): 1134-1139.

33. Bernstein CN, Papineau N, Zajaczkowski J, Rawsthorne P, Okrusko G, Blanchard JF. Direct hospital costs for patients with inflammatory bowel disease in a Canadian tertiary care university hospital. $\mathrm{Am} \mathrm{J}$ Gastreoenterol. 2000;95(3):677-683.

34. Nguyen GC, Tuskey A, Dassopoulos T, Harris ML, Brant SR. Rising hospitalization rates for inflammatory bowel disease in the United States between 1998 and 2004. Inflamm Bowel Dis. 2007;13(12): 1529-1535.

35. Bassi A, Dodd S, Williamson P, Bodger K. Cost-of-illness of inflammatory bowel disease in the United Kingdom: a single-centre retrospective study. Gut. 2004;53(10):1471-1478.

36. Cramer JA, Roy A, Burrell A, et al. Medication compliance and persistence: terminology and definitions. Value Health. 2008;11(1):44 47.

37. Stein DJ, Ananthakrishnan AN, Issa M, et al. Impact of prior irregular infliximab dosing on performance of long-term infliximab maintenance therapy in Crohn's disease. Inflamm Bowel Dis. 2010;16(7): 1173-1179.

\section{Dovepress}

optimize clinical outcomes for existing disease states are major areas of interest. This journal has been accepted for indexing on PubMed Central. The manuscript management system is completely online and includes a very quick and fair peer-review system. Visit http://www.dovepress.com/ testimonials.php to read real quotes from published authors. 